Journal of Engineering Sciences, Assiut University, Vol. 37, No. 5, pp. 1235-1251, September 2009.

\title{
THE VERNACULAR AFFILIATION BETWEEN CONCEPTS OF SOCIAL JUSTICE AND ITS IMPACTS ON DESIGN-RELATED AGENDAS
}

\author{
Hally El Kony and Ghada El Kony \\ Department of Architecture, Faculty of Fine Arts, University of Alexandria
}

(Received June 23, 2009 Accepted August 16, 2009).

\begin{abstract}
The paper depicts two main design approaches that are emanated from the ethics of social justice, i.e., the inclusive design and the sustainable design. Despite the significant advancement of these approaches in theory and practice, they haven't generated yet substantial design guidelines and regulations for public and/or residential settings that are pertinent to the real practice of design-related professionals, especially architects and interior designers. For this purpose the paper investigates /whether the 2 approaches are two sides of the same coin or are disparate set of ideas with totally separate agendas. It draws up the distinctiveness and disparity as well as the affiliation of their related concepts. The paper ascertains a tangible relationship that exists between the 2 approaches of social justice which enables an appropriate and unified field theory and practice. It also suggests an operable and inclusive agenda for design problem-solving based on the universality of design as an integrated dimension of social sustainability with the main purpose to ensure full participation and equal opportunity for every person in society. Finally, an exposure of some of the impediments that encumber the advancement of this agenda is sketched out.
\end{abstract}

KEYWORDS: Social equity, Inclusive design, Sustainable design, Social sustainability, Design agenda

\section{1- INTRODUCTION:}

The present study focuses on design disciplines that adopt considerations of, and concern with equity and social justice. Justice is complex and multi-faceted phenomenon of human society that plays a central role in every domains of life. In fact, all disciplines, regardless of their nature are confronted to a certain degree with justice (Azer, 92; Lerner, 77; Miller, 76; Mikula, 80, Walster, 78). The definition of equity and social justice depends on the moral principles and the social context within which it exists (El Kony, 2004). The literature illustrates that equity is related to the allocation of goods whereas social justice implies impartiality in every aspect of society (i.e., material and immaterial goods or resources of positive or negative value) (Austin et al., 1980; Miller, 1976). Different political parties, however, are likely to embrace human rights and welfare safety as major constituent of social justice (Mikula, 80).

Design is a powerful tool for social justice; many studies assert the built outcome is a form of social engineering that shapes society, mediates the likelihood of choices and controls or prevents behaviors. Accordingly, designers have to use their expertise to provide opportunities for social change (Winhall, 2008).Robinson supports 
this viewpoint by stating that the built environment communes everyone's status and suitable roles according to the conventional values of the society and that in case any cultural change is needed, design interventions reinforce and support this change "..... as they represent- in a powerful form- what ought to be." (Robinson et al., 1999, p.269). Accordingly, the physical design of communities is imperative to promote any value and ethics since the everyday interactions with design features create a proactive educative environment that eventually informs the inhabitants to adopt choices and lifestyles leading to better health, well-being and quality of life. Social justice allows every person to be independent, to have control over one's life and to pursue one's goals efficiently (Gewirth, 1983). El Kony stated that to reach these goals, interventions should be made on both the person and its surrounding physical, social and cultural environment to provide all people essential support to enables them to fulfill their basic needs and to participate in community activities. The author also pointed out that the variation or the controversy exists mainly in the implementation strategies to be adopted.

As such, the paper depicts two social justice-related disciplines: sustainable design and universal design (also known as inclusive design). The two disciplines have witnessed substantial improvement in theory and practice during the last decades. However, the existing literature fail to provide comprehensive design guidelines and regulations for public and/or residential settings that are pertinent to the real practice of design-related professionals and that ensure social justice for all its members. Therefore, the paper investigates whether the 2 disciplines have disparate set of ideas with totally separate agendas or if they are two sides of the same coin thus enabling an appropriate field of theory and practice that ensures full participation and equal opportunity for everyone in society. Our hypothesis is that universal design and sustainability communicate comparable set of ideas and thus can engender similar design strategies. For this purpose, we will inquiry the rationale, definitions and purposes of the 2 disciplines in order to sketch out the distinctiveness and disparity as well as the affiliation of their related concepts through an analysis of different reflections of the 2 disciplines as elaborated by literature. The inquest will also try to link these issues to the main societal and political mainstream in order to determine to what extent the existing perception and design interventions are determined by these concerns as matching up to other motivations. Subsequently, we will identify the major shortcomings in research and practice related to the 2 disciplines followed by an illustration of endeavors to associate between them. Then we will present a suggested design strategy that provides social equity with an exposure of some of the impediments that encumber the advancement of this strategy. At the end of our research, we will. As a wrap-up, we will provide the necessary conclusion for the materialization of the study and pinpoint a number of areas necessary for improvement

\section{2- SUSTAINABILITY VERSUS UNIVERSAL DESIGN:}

\section{1- Sustainability:}

The concept of sustainability was first introduced in the early 70th to define societies that grant most favorable achievement to its members (Goldsmith et al. 1972, p.23). Yet, sustainable development with its related dimensions wasn't claimed as a key 
political end until the publication of "the "Brundtland report: Our Common Future by the World Commission on Environment and Development" in 1987(WCED 1987). The report urge the need for improvement of the quality of life "for all" as a precondition for a sustainable society and insisted on building comprehensive approaches that integrate environmental, economic, and social issues to tackle communal problems. This perception stresses the notion of equity for all present and future generations regardless of their differences, and puts a premium on fulfilling the essential needs of the world's underprivileged (ibid., p.43). Further to the Earth Summit that was held in Rio in 1992, the Agenda 21 program was set up, requiring all signatory states to draw up national plans on sustainability. One of the main elements of sustainability 1 is to accomplish social and economic equality and equity for all members of the society (Blowers, 1993). Equal opportunity to social, economic, health and education services is thus a civil right that every citizen regardless of his or her functional limitations should have.

Despite the controversy in the definition of sustainability, there is an international consensus of sustainable development as the only acceptable form of development and that in order to achieve successful policies and investments one must deal with environmental, economic, and social factors and the interrelationships between these (Williams 1994). In fact, the Brundtland report categorizes sustainable development into three interconnected disciplines: environmental sustainability, economics sustainability, and social sustainability. This later is also called social equity (Robinson and Van Bers 1996, p.iii). In 2005, The United Nations emphasized this classification in its "World Summit Outcome Document". As shown in the document, economic development, social development, and environmental protection2 are the" interdependent and mutually reinforcing pillars" of sustainable development (figure 1).

The United Nations acknowledge that everyone has inherent intrinsic rights and needs that decision-makers have to consider and respect. As asserted in the Brundtland report, the concept of sustainability aims to provide the means to fulfill these needs equally (WCED 1987).

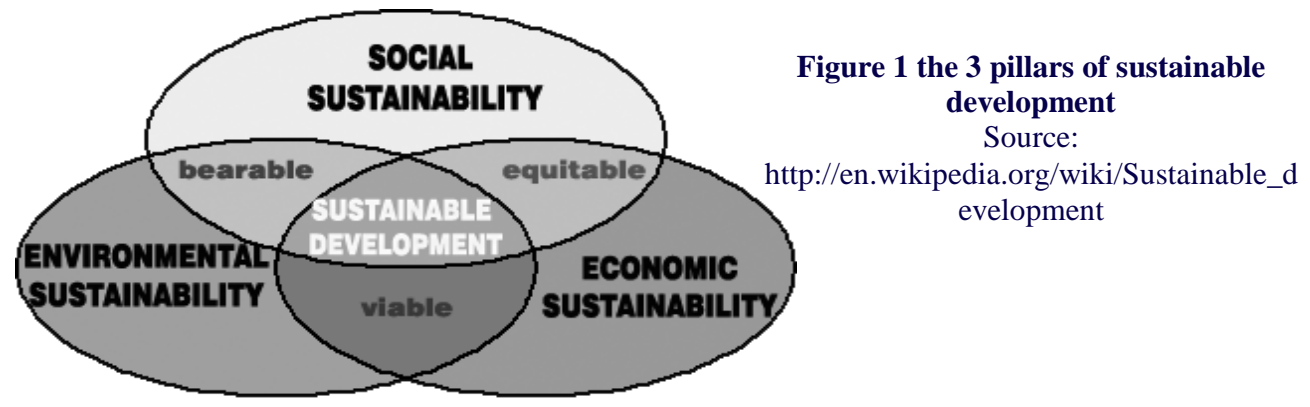

(1) Sustainability comprises 4 elements:

- To conserve the stock of natural reserve;

- To avoid damaging the regenerative capacity of ecosystems;

- To achieve greater social and economic equality and equity;

- To avoid imposing risks and costs on future generations. (Blowers, 1993 in Greed, 1999, p.6)

(2) A fourth pillar for sustainable development is Human sustainability introduced by Daly, H.E. (Goodland, R.,). For further information read Daly $(1973,1974,1992,1996,1999)$ and Daly and Cobb (1989) 
In summary, we will deal with sustainability as a set of environmental interventions that enable all members of society to fulfill their needs and convey their potential to the fullest in the present while planning and acting in a long-term manner. The concept of sustainability implies working toward a balance between the needs of all people, present and future, and the needs of the environment, in part because the environment is the source that provides for all human needs. It implies that social progress and economic development depend in part on conserving natural resources and protecting natural systems.

As for the social sustainability or social equity, it involves a social responsibility to prevail over physical and social environmental deficiency. In fact, the surrounding environments consist of not only the hard structure that defines the external and tangible form but also population with diverse culture, characteristics and needs of physical settings in which they perform their daily activities. It emphasized the well-being of individuals and the quality of their lives and therefore, the constancy of the society. Social sustainability is built on the principles of equity, social inclusion and interaction, security, and adaptability (City of Vancouver, 2006). Other related aspects to social sustainability are human rights, respect of cultural diversity Individual autonomy and freedom from oppression. A sustainable designed setting is the one that preserves human dignity and meet all of this diversity. These aspects have their considerable impact not only the quality of people's lives but also environmental quality and political stability (Haughton 1999). Hancock assumed every member of a society is able to make social investments depending on the available "stock" of social and human resources. He also identified a socially sustainable environment as the one that comply with some conditions as shown in figure 2 (Hancock,; Lennard and Lennard, 1987).

The social component of sustainability aims to achieve an appropriate level of functionality of the environment by fulfilling the fundamental needs of its diverse residents. Such environment has to be easy to sustain and build with its local assets and have the flexibility to predict present and future problems and set the necessary circumstances to alleviate and/or prevent these problems.

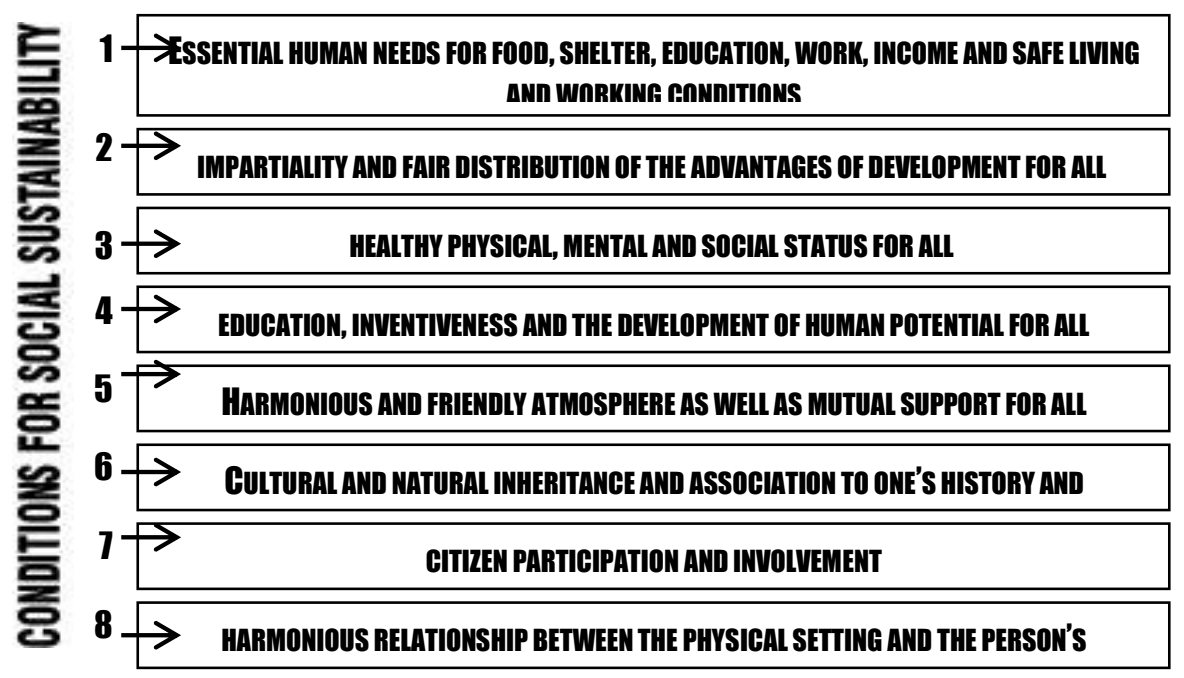

Figure 2 Conditions for social sustainability (Source: Derived from Haughton. 1999.) 
As seen in figure (3), social sustainability is achieved via a balanced person/environment relationship:

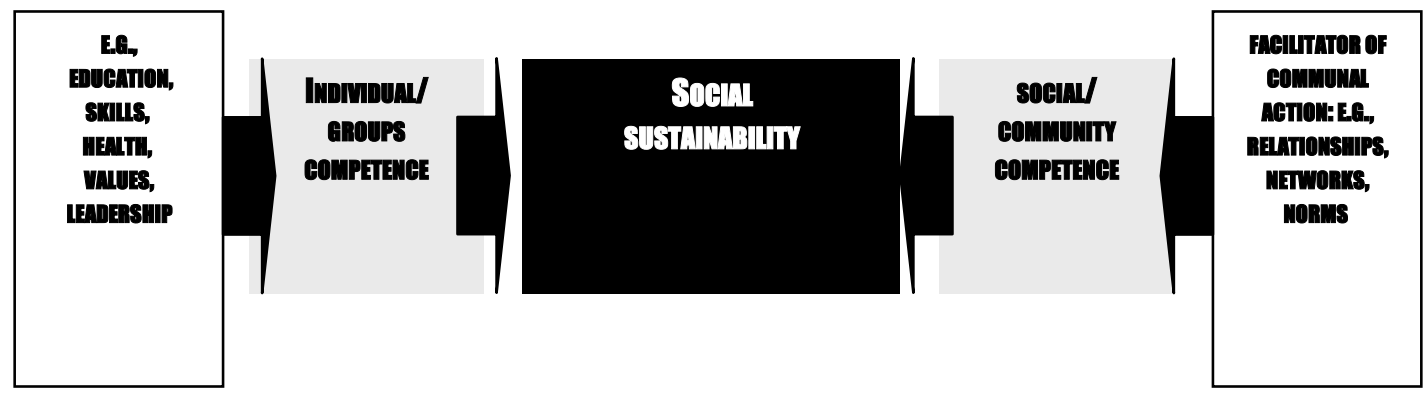

Figure 3 Person/Environment variables for social sustainability Source: Derived from City of Vancouver, 2006

According to this perception the person/environment resources and attributes are fundamental catalysts of the individual and communal wellbeing as well as the overall quality of life. These catalysts should comply with four guiding principles: (1) equity, (2) security, (3) social inclusion and interaction and (4) adaptability.( The Norwegian State Council on Disability supports these conditions by defining social sustainability as maintaining social capital (i.e., the essential structure of society including services and investments). Daly points up that equal rights along the shared values 1 of any society stocks up and maintains the social capital and prevent it from depreciation (Daly, 1996; 1999).

\subsection{Universal design:}

Universal Design is human-centered design that imparts an applicable agenda for shaping the attributes of the built environment and products to be usable by the broadest range of users regardless of their characteristics, abilities and/or activities or situations. Universal design is a shift from the narrow scope of accessible design for people with disabilities to broader and more inclusive design that embrace diversity in social and economic circumstances as well as variation in age and ability (all available name).The universal design is catching up to this international demographic shift and provides contextual design- problem solving that are dynamic over time and based on the understanding of the factual transactional outcomes of the person and its physical, cultural and social environments (Adaptive environments, 2006).

Universal Design refers to the design of products and environments that are usable by all people, regardless of age or disability, to the greatest extent possible without the need for adaptation or specialized design (Mace, 1985). Universal Design recognizes that functional limitations - whether physical, sensory, communicative or cognitive - are not exclusive to people with disabilities and are recognized as contextual variables that are dynamic over time and circumstances.

(1) Cohesion of community for mutual benefit, connectedness between groups of people, reciprocity, tolerance, compassion, patience, forbearance, fellowship, love, commonly accepted standards of honesty, discipline and ethics (Daly, 1999) 
El Kony asserted that the universal design approach is the best architectural approach that guarantees easy and equal use of all design features to all type of users. According to the author, the universal design focuses on the social impact of the built environment. In theory, the precise implication of the universal design can result into a matching between the demands of the built environment and the personal competence of its users. This ideal transactional relationship equally enables all types of users accomplishing their desired activities without stigmatizing and/or unduly separating some type of users from the main pattern of the setting use (El Kony, 1997; 2004).

As shown in table 1, the Principles of Universal Design define universally designed products and environments as being (1) equitable in use, (2) flexible in use, (3) simple and intuitive to use, (4) easy to perceive, and (5) tolerant of error as well as (6) requiring low physical effort and (7) being better sized and arranged to accommodate all users (Connell, et al, 1997)

\begin{tabular}{|c|c|}
\hline $\begin{array}{r}\text { PRINGIPLES OF UNIVERSAL } \\
\text { DESIGN }\end{array}$ & DEFINITION \\
\hline EQUITABLE USE & THE DESIGN IS USEFUL AND MARKETABLE TO PEOPLE WITH DIVERSE ABILITIES \\
\hline FLEXIBILITY IN USE & $\begin{array}{l}\text { THE DESIGN ACEOMMODATES A WIDE RANGE OF INDIVIDUAL PREFERENGES } \\
\text { AND ABILITIES }\end{array}$ \\
\hline $\begin{array}{l}\text { SIMPLE AND INTUITIVE } \\
\text { USE }\end{array}$ & $\begin{array}{l}\text { USE OF THE DESIGN IS EASY TO UNDERSTAND, REGARDLESS OF THE USER'S } \\
\text { EXPERIENGE, KNOWLEDGE, LANGUAGE SKILLS, OR CURRENT CONGENTRATION } \\
\text { LEVEL }\end{array}$ \\
\hline $\begin{array}{l}\text { PERGEPTIBLE } \\
\text { INFORMATION }\end{array}$ & $\begin{array}{l}\text { THE DESIGN GOMMUNICATES NECESSARY INFORMATION EFFECTIVEIY TO THE } \\
\text { USER, REGARDLESS OF AMBIENT CONDITIONS OR THE USER'S SENSORY } \\
\text { ABILITIES }\end{array}$ \\
\hline TOLERANGE FOR ERROR & $\begin{array}{l}\text { THE DESIGN MINIMIZES HAZARDS AND THE ADVERSE GONSEQUENGES OF } \\
\text { ACGIDENTAL OR UNINTENDED ACTIONS }\end{array}$ \\
\hline Low Physical EFfort & $\begin{array}{l}\text { THE DESIGN GAN BE USED EFFICIENTLY AND COMFORTABIY AND WITH A } \\
\text { MINIMUM OF FATIGUE }\end{array}$ \\
\hline $\begin{array}{l}\text { SIZE AND SPACE FOR } \\
\text { APPROACH AND USE }\end{array}$ & $\begin{array}{l}\text { APPROPRIATE SIZE AND SPACE IS PROVIDED FOR APPROACH, REACH, } \\
\text { MANIPULATION, AND USE REGARDLESS OF USER'S BODY SIZE, POSTURE, OR } \\
\text { MOBIIITY }\end{array}$ \\
\hline
\end{tabular}

TABLE 1- THE 7 PRINCIPLES OF THE UNIVERSAL DESIGN

Universal Design, representing a paradigm shift from the accessibility approach, broadens the scope beyond those accessible design interventions that tend to accommodate certain user groups at the expense of others and instead focuses on built environments and design features that are equally usable by everyone (EL Kony et al., 2004). Universal Design enhances the minimal requirements of accessibility laws by expanding the limited scope of accessible design to embrace additional qualities such as equitable use, safety, functionality, flexibility, etc. A universally designed facility can thus enable full and equal participation of everyone in the activities that designed environments afford. 


\subsection{Shortcomings of Research and Practices Related to the 2 Concepts}

There are major shortcomings that create conflicting, inaccurate, and sometimes deliberately misleading reading and assessment of existing practice and policy related to sustainability and universal design. Giving the fact of the constant debate and confusion about the reality and origin of the 2 concepts, this sub-section elucidates the major shortcomings related to the 2 concepts that designers and researchers need to overcome.

The term sustainability with its related pillars has never found an agreed and explicit definition that helps to put the concept into operation. On one hand, different interpretations of the concept include the economic, environmental, and social aspects but emphasize them to varying degrees (Toman 1992). Sometimes the term is used in a narrower sense that shrink it into a limited variables (e.g., using earth-friendly materials, waste reduction, energy reduction, recyclable packaging) (Voinov, 1998 ). Haughton, 99, adds that the emphasis is constantly put on economic development (Haughton, 1999). This situation creates conflicting and uncertain findings and has led to confusion and contradictions, in research experiments and methods and even at the level of international sustainable development declarations (Satterthwaite 1999). As Voinov stated, the means with which sustainability is perceived and interpreted is mostly related the knowledge and professional background of the perceivers and applications (Voinov, 1998). The author also noted that sometimes, the term is used without a clear acknowledgment of its accurate significance and implication. Other researchers assumed that most scientific studies regarding the concept of sustainability are redundant and ambiguous and conveys ideological and political concerns rather than scientifically supported ones (Ghilarov, 1996, Voinov, 1998). On the other hand, social sustainability has received less attention than the concept of environmentally sustainable development (Haughton 1999; Satterthwaite 1999). As Ayres noted, there is no feasible goal relate to social sustainability (Ayres, 1996). In fact, most of the literature we used in the course of our research comprises abstract socio-political suggestions related to the concept with no scientific definitions and quantifiable indicators that facilitate the application and assessment of interventions. Finally, in order to indicate the extent to which any practice or policy is in compliance with sustainability principles, it is imperative to provide precise indicators to measure how sustainable an individual, company, community, or country is and how much progress is being made over time. Although some tools for measuring these types of progress exist, that they are still in need for improvement and refinement (Milbrath, 1996).

Contemporary EB research on universal design faces parallel concerns. Although there is a worldwide consensus on the seven principles that underlie the design of universally usable environments, we have identified many shortcomings of transactional theories and related measurements allied to the usability of the built environment that hinder the development of the new approach: The shift from the limited implications of accessible design towards a more inclusive design approach postulates different conceptual models that acknowledge the diversity and the dynamic nature of both personal and environmental variables. However, many studies on universal design fail to acknowledge more than a few of them when attempting to examine universal design and its practice (El Kony et Al., 2004). In fact, one can easily detect to how far universal design is misapprehended is reduced to only few basics of 
access (a ramp at the main entrance and a 1.50 meter turning radius) (El Kony, 1997; 2004, El Kony et al. 2004)). Other researchers assert the concept, due to this limited perception, is introduced as an appendix for building regulations and as marginal design criteria just prior to the end of the design process instead of being considered as a primary basis of civil rights that enlighten the whole design process (Lindberg, 1996, Sandhu, 1995). Besides, there are few studies that address the implementation of the universal design into practice. The UD approach is still described in most studies as a set of idealistic values and beliefs rather than an objective interpretation of the users' needs and abilities from a technical perspective. Furthermore, few studies suggest tools for measuring the level of conformity with the Principles of Universal Design while the rest present Universal Design as a slightly disguised version of the predominant concept of accessibility.

\section{4- THE ASSOCIATION BETWEEN SUSTAINABILITY AND UNIVERSAL DESIGN:}

During the last few years, the terms of "sustainable design" and "universal design" are used concurrently. The literature shows many endeavors made to connect between the principles of social sustainability and Universal design at many level whether in theory, policy and design practice. Sahdhu, 2001, 02, associates sustainability with universal design and call for a multi-disciplinary tactic that sets a usable and easy-to use criteria to implement in the building industry (Sandhu, 2001, 02). Jones et Al. share the same idea by arguing that sustainable design is an environmentally responsible design that involves a global approach to addresses the interrelationships of design and human behavior. This view insists on considering universal design as an integral part of sustainability that considers the needs and the quality of life of all users.(Jones,et Al., 2004).

The Copenhagen Declaration on Social Development (1995) set up the term "people-centered sustainable development". The Declaration referred to a multidisciplinary strategy to support universal design as an acknowledged pillar to the aims of social sustainability and insisted on initiating prospects for exchanges between the developed and developing nations. However, the declaration doesn't directly deal with design- related issues but emphasizes primary insights to guarantee human rights for people with disabilities.

The Chapter 7 of Agenda 21 investigated the possibility to enhance equal social, economic and environmental quality of human settlements and the living and working environments of all people via the provision of adequate shelter for all. The major goal of the program is to provide satisfactory residential setting via an assistive environmentally sound method. This comprehensive approach for housing has been restricted to adequacy and security criteria that are mainly addressing the so called "disadvantaged and marginalized groups" such as the homeless, refugees and asylum seekers, elderly people and people with disabilities.

One of the leading endeavors to apply the principles of the universal design as a component of social sustainability is the Smart Housing project initiated by the Queensland Environmental Protection Agency, in conjunction with the Australian Greenhouse Office. According to the project, A Smart House embraces the environment, economic and social aspects of sustainability whereas this later 
implicates user-centered approach to build universally designed, safe and secure residential units (see figure 4). As shown in this figure, the safety and security criteria are exclusive of the general implication of universal design as the project restricts the scope of the term to only flexibility and comfort measures to suit a variety of personal abilities at different stages of their lives (Queensland Government, 2004)

This confusion between accessibility and universal design has also affected strategies adopted by many countries integrate universal design into sustainability. For example, the Norwegian white paper on housing policy has introduced a Programme of Action for Universal Design in 2002. Instead of focusing on the real meaning of the concept, the program focuses on providing accessibility for people with disabilities and to improve the functional qualities of residential environments and infrastructure via making it possible for disabled citizens to live in ordinary residential areas.

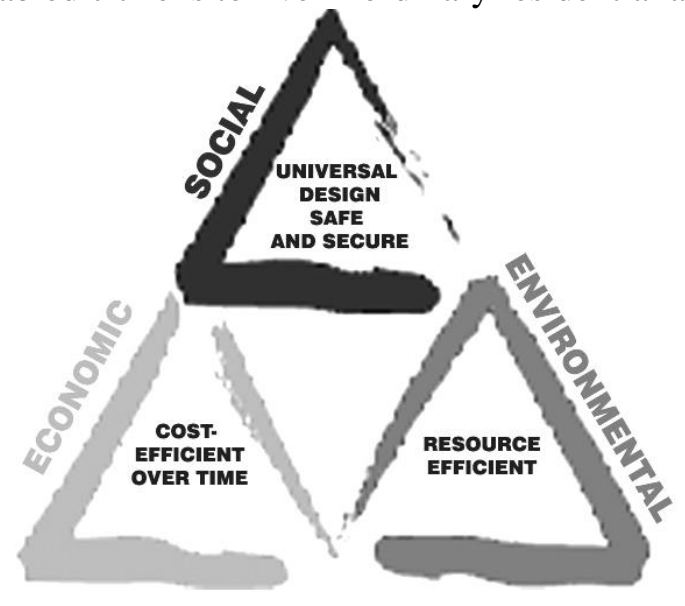

Figure 4 Dimensions of the Smart Housing program

Source: www.smarthousing.qld.gov.au

Another example is the Ontario Trails Strategy for the design, construction and maintenance of trails. The strategy identifies Sustainable and Universal Design as the guiding principles for usability of trails for all (City of Vancouver, 2006). While the definition of universal design and social sustainability put forth in the strategy seems alike1., they are classified as two separate entities. Besides, the means with which the two issues are put into operation are disparate, thus maintaining the typical segregation

(1) a- Social sustainability is built on the principles of equity, social inclusion and interaction, security, and adaptability. Trails are socially sustainable when they are enjoyed and supported by a large, diverse proportion of the community. (City of Vancouver. Definition of Social Sustainability. [Online] $\quad$ Retrieved $\quad 31 \quad$ July 2006 from http://vancouver.ca/ctyclerk/cclerk/20050524/documents/p1.pdf)

b- Universal design is a philosophy that attempts to meet the needs of the widest possible range of potential users. It means considering the needs, interests and abilities of everyone, not just those "like us" or "most expected", from the very beginning of the design process. Universally designed facilities can be enjoyed by people of all abilities (Center for Universal Design. (2005) What is universal design? [On-line] Retrieved 31 July 2006 from http://www.design.ncsu.edu/cud/about_ud/udprinciples.htm.) 
between the 2 concepts. Furthermore, the implication of social sustainability didn't involve tangible and easy-to apply design measures that achieve any of its objectives. Instead, trails, as described in the strategy, are socially sustainable if they are supported by a specific community that trusts in the profit of trails and that will make effort to defend and improve the opportunities that trails afford (City of Vancouver, 2006 ).

Many academic endeavors are made to advocate this marriage between the 2 concepts. The Center for Universal Design for example has launched the yearly North Carolina Sustainable Building Design Competition for its students. The competition includes universal design as part of its design criteria. The Design Competition reinforces the connection between universal design and sustainable design (Center for universal Design, 2008)

Also in 2007, the Florida State University- College of Visual Arts, Theatre, and Dance have supported a symposium entitled "Art and Design for Social Justice". The proceedings show a considerable attempt to link between social justice, social sustainability and universal design in favor of creating a better quality of life for all members of society (Florida State University, 2007).

\section{REFLECTIONS ON THE SOCIAL SUSTAINABILITY/ UNIVERSAL DESIGN MERGER:}

In view of that, we can confirm the hypothesis that the workable facet of social sustainability, the one that can add a valid and inclusive implication to the concept is that of the universal design. The universal design associates with sustainability at similar progressive standpoint: universal design is a lifespan approach that offers design problem solving based on a responsibility to the human experience and to the surrounding environment, it involves a deeper recognition of interconnections of E/B variables and of the necessity to approach any issue in light of those connections. It presents a change of attitude from dealing with e/b problems on a case by case basis, to make design decision that enables social equity, full participation and social integration in a healthy and secure physical environment

Universal design is thus the only discipline that can introduce social sustainability as a feasible, extensive, integrated approach that is able to generate valuable design strategies and results. In fact no other direct and clear-cut conception but universal design is able to symbolize social sustainability in terms of providing an agenda for action to re-establish impartiality and improve social equity.

Therefore, we propose to support the universal design principles by integrating its related guidelines into a global approach for managing and designing public and residential settings through a sustainable-design filter.

Yet, as shown in the discussion, the complexity and extent of the current perception of sustainability and universal design continue to challenge designers and policy makers. The universal design concept has not reached its concrete and operational form which is a prerequisite for the development of accurate UD guidelines. Also, there is a pressing need for better techniques for measuring and evaluating the physical environment at the descriptive, analytical and diagnostic level. The development of one valid and comprehensive measure instrument to evaluate design features' conformity with the seven Principles of Universal Design would significantly improve the research designs of such studies. 
For this purpose, we are suggesting a strategy for integrating universal design in the sustainability-related practice that can provide quantifiable interpretation of the complex phenomena of e/b transactions with regards to environmental responsibility perspective and that can be examined and assessed by means of valid and reliable methodology and presented as a simplified but meaningful quantitative data. The strategy once refined can be extremely comprehensive, be relevant to current policy issues, and suggest significant information in forms understandable and useful to design-related professionals and decision-makers.

\section{5- THE SUGGESTED STRATEGY FOR CREATING UNIVERSALLY DESIGNED ENVIRONMENT:}

In order to bring the universal design principles into practice, designers must conceive each setting of their projects as an organization with specified short and long term goals along with potential users with well-identified personal attributes, determined activities and desired behavior. This will help identifying the way people use or eventually use the space, as well as the social and cultural organizations of every specific setting. The strategy we suggest builds on the two following issues:

1- The users' demands that are translated into daily life tasks. That comprises personal and cultural identity, interrelationship between users, evolving mastery of the specific setting);

2- The daily activities and related tasks that must be matched with the design attributes through a better analyze of the transactional relationship between the environmental demands and the personal characteristics and the functional limitations of the users.

The suggested strategy embraces the following dimensions (EL Kony, 2004):

1- The Performance Prediction Model (PPM) of individual users' transactions with universally designed building features;

2- The Universal Design Compliance Guidelines (UDCG) for universally designed settings;

3- The Universal Design Audit (UDA) for assessing the performance of building features with respect to the principles of the Universal Design.

\subsection{The Performance Prediction Model:}

The Performance Prediction Model (PPM) was first introduced in 2002 (El Kony et al. 2002). It is a comprehensive model of individual users' transactions with universally designed building features. The PPM assumes that the physical environment can afford either desirable or undesirable outcomes for an individual and that the outcomes afforded depend on the characteristics of the environment relative to the personal characteristics (e.g., size) and the functional abilities (e.g., mobility) of its individual users. As shown in figure 4, if building features' design attributes (e.g., ambient environment, organization of the setting, physical characteristics, etc.) conform to the Principles of Universal Design, this should generate equilibrium between the users' functional abilities and the demands or challenges presented by the environment.

This should make it possible to operationally define the seven Principles of Universal Design and significantly decrease criticisms about the Principles' vagueness. It should also lead to a better understanding of environmental problem-solving since it 
will create positive architectural solutions that enable preferred behavioral outcomes i.e., in the case of Universal Design, universal usability. By adopting this model in research and practice, users' diverse personal characteristics and functional abilities will be explicitly acknowledged as significant factors when designing environments to ensure their universal usability. Moreover, this model will hopefully help shift the paradigm from designing "special interventions" for "special populations" (i.e., accessible design) to designing more inclusive environments that enable all users, regardless of their personal characteristics or functional abilities, to participate fully and equally in all the setting's activities (i.e., universal design).

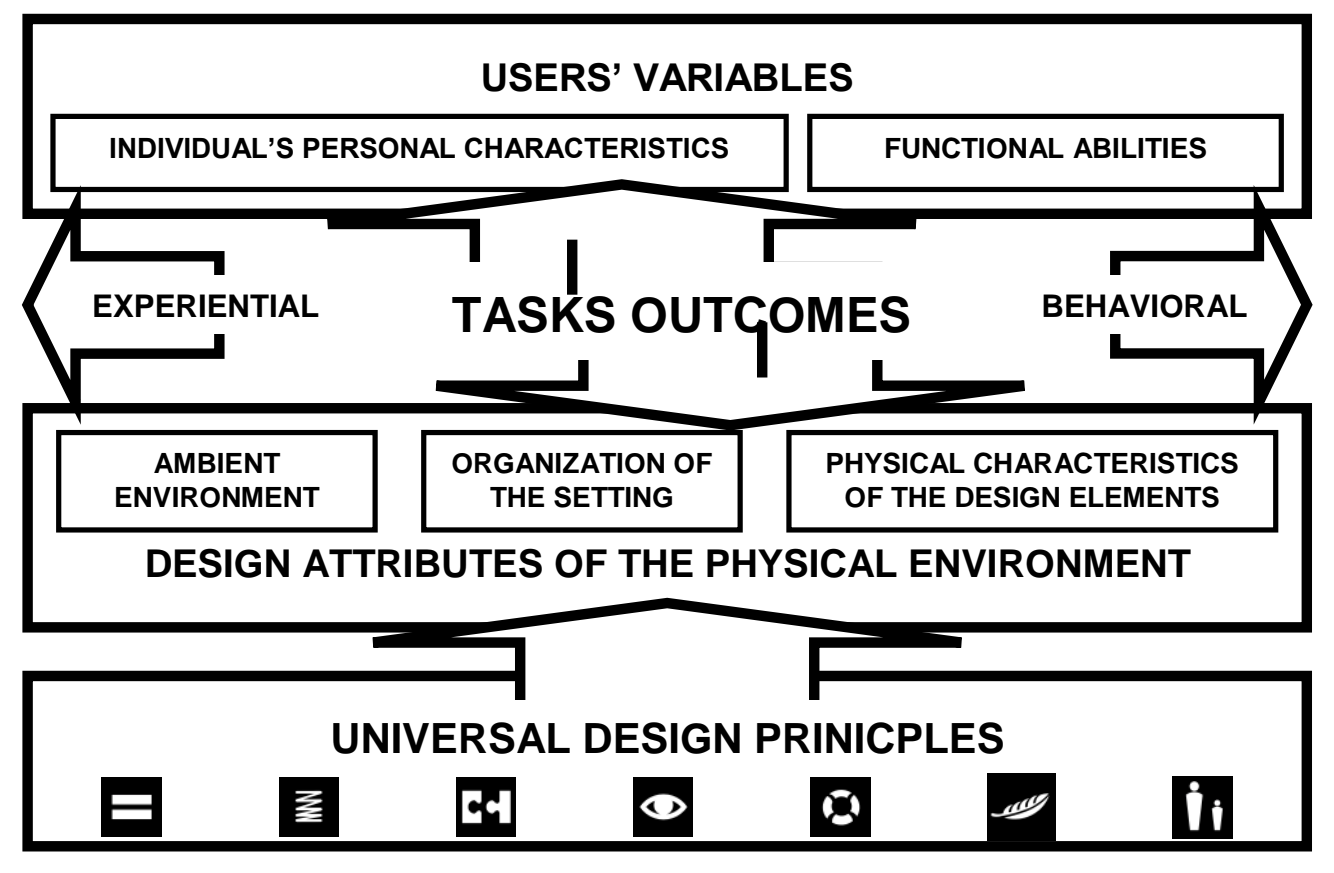

THE PERFORMANCE PREDICTION MODEL

Figure 5 The conceptual framework for the Performance Prediction Model

Source: El Kony et al. (2004).

\subsection{The Universal Design Compliance Guidelines:}

The Universal Design Compliance Guidelines (UDCG) represents an inclusive and convenient way to create user-friendly settings for people of all ages, sizes and abilities and includes the changes that all people experience throughout their lives without risking sacrificing extra financial charges or major changes of the design concept. The UDCG are drafted to embrace the entire population in all its diverse and complex varieties, offering creative solutions and alternatives to enable the complete usability of indoor and outdoor setting. Once this variation is taken into account, the evident solutions and alternatives to create a universally designed setting become obvious. This can consequently promote advanced and productive reflections vis-à-vis universally designed environments. Such process, which reaches many influential decisionmakers, can raise awareness of the many social, cultural and economic benefits of 
designs that satisfy all users regardless of their abilities and needs. The suggested guidelines and evaluation tool were conceived in a way that is adaptable to the developing countries. Away from any dictating style, the guidelines were carefully written to enable designers to use their full imagination and potential to create unlimited number of design features and products that are universally usable.

\subsection{The Universal Design Audit:}

The UDA enables environment/behavior transactions to be not only predicted but also quantified. In this fashion, it provides a reliable and valid diagnostic tool for measuring conformity of design feature with the seven Principles of Universal Design and to envisage its usability for specified activities. This empirical identification of observable indicators of Universal Design compliance for specific building features will notably reduce the often criticized vagueness of the current Principles of Universal Design. The UDA is still requiring more improvements. Nevertheless, it represents an indication of what the future universally usable environments might be.

\section{6- CONCLUSION AND DISCUSSION:}

The design experience is enhanced via an understanding and integration of human potential and human equity issues. Adopting a user-centered approach is a fundamental step to change conformist environmental perception and decision-makings that prevent many groups from enjoying their rights of full participation and social integration. As such, designers should recognize the ethical consequences of their decisions and treat their professions as a "social art"1 that cab shape built settings tolerate and acknowledge every member of society regardless of its personal characteristics, functional abilities, values, behavioral norms, as well as social and spatial patterns.

Universal design means that everyone matters. It recognizes everyone has the same needs, rights, dreams and aspirations but may need different means to fulfill them. That doesn't entitle any designer to exclude any person or groups from the mainstream society through inconsiderate designs. And thus integrating and merging these means in the overall design conveys a societal accepting of these groups as equals and enables a positive experience of social integration and full participation.

Thus, by integrating the universal design as an alternate terminology for social sustainability, we will give the opportunity to many interested parties to better understand and integrate sustainability in their professions and to assume their roles and responsibilities to create physical settings supportive of human rights and social justice. This merge will also overcome many of the current shortcomings related to the concept. Via a better proficiency, appropriate use of resources along with a usercentered approach of design, it is possible to engender innovative solutions for a sustainable quality of life for a considerable percentage of the world's population.

The strategy for universal design suggested in this paper could be a phase en route for a comprehensive reconsideration of the building legislations to be in line with the principles of the universal design. The minimal requirements of accessibility will be straightforwardly enhanced by expanding the limited scope of accessibility to embrace the new qualities of the universal design approach such as equitable use, safety, functionality, flexibility, etc. 
Yet, our society knows very little about the functional and socio-psychological limitations related to design. We should acknowledge that increasing the public awareness of universally usable environment and sustainability related benefits is a critical step towards a better implication of the 2 concepts in building industry. If truth be told, there have always been achievements and rights acquired via people's attitudes rather than through laws. This public awareness can force service providers to switch their philosophy towards universal design and will eventually eradicate the conventional design approach and practice.

A plan of action should be taken to create positive change of attitudes at global and specialized level:

The global level should aim to eliminate the prejudice regarding people with functional limitations and to ameliorate their public image. We suggest the establishment of a national council to monitor the compliance of sustainability in all service delivery. The council should work as a coordinator between different sectors of service delivery for all user groups. It should also work as a adviser and a general policy organizer for all the governmental authorities and organizations related to this issue. One of its major divisions should be concerned with the planning and building design.

The aims of this council should be as followed:

1- To monitor and assess the performance of the local planning authorities and building control authorities regarding the universal usability measurements with respect to the provision of the planning and building permission;

2- To gather reliable information useful for research and for practice;

3- To provide information with particular reference to access for people with functional limitations and to ensure accessibility and usability considerations are taken into place;

4- To coordinate between local authorities and user groups, thus increasing participation and inclusion within the urban planning and building design system;

5- To finance all research related to environment-behavior research and to ensure the dissemination of the results of these studies.

Besides, all media sources (e.g., the print media, television and radio programming, etc.) should focus on introducing all members of society regardless of their socio-economic background, personal characteristics and functional abilities as a productive and competent member who could accomplish their social tasks.

As for the design level, the standpoint of design-related actors towards the complex relationship between the built environments and their users should be changed. We take this opportunity to encourage design schools to relate their curriculum with social and political agendas and teach the professors, prior to the students, new ways to approach societal issues that enable direct implication in design problem solving.

A critical step towards implementing strategies for universally designed environments is to integrate environment-behavior studies and universal design as compulsory courses for the undergraduates and the graduate students. This step is the most preeminent and efficient way to create generations of designers who are aware of the economic, social and cultural impact of their designs. By training these students the right skills and techniques to translate these realities into design products and settings, the educational system will assume its social responsibility to ameliorate the social 
integration and the quality of life of all type of users and be recognized as an indispensable form of the social support system. Faculty members themselves should be also well informed about and highly trained in the basics of the environmentbehavior theories and methods. The training will also include training in the participatory design as well as the principles, the guidelines and the evaluation tools of the universal design.

Finally we hope the paper leads to develop such a universal design educational package that can be taught in all schools of architecture and urban planning. It is important to mention that the universal usability is a relatively new track that needs to be explored by design-related groups. It is a multidisciplinary approach that involves wide areas of expertise and interests groups (i.e., transportation, demographic studies, sociology, psychology, human factors, etc.). This collaboration is crucial to create universally designed settings. The paper can be thus the first basis of a long term research project initiated by academic institutions in collaboration with other local and regional interested organizations. The project will focus on eradicating architectural barriers and creating universally designed products and design features, thus being a model to be followed by other nations.

\section{REFERENCES:}

(1) Adaptive Environments, 2006. What is Universal Design? Boston, USA Adaptive Environments Center..

(2) Azer, A., \& Afifi, E., 1992. Social Support Systems for the aged in Egypt. Tokyo: United Nations University Press.

(3) Bridge, C. Universal design impacts housing sustainability: Cost-benefit evidence- The University of Sydney from www.homemods.info

(4) Blowers, Andrew, ed. 1993. Planning for a Sustainable Environment: A Report by the Town and County Planning Association. London: Earthscan. A thorough if dry consideration of urban planning aspects of sustainable development from a British point of view, with emphasis on environmental policy rather than design.

(5) Brundtland Commission, United Nation's World Commission on Environment and Development. 1987. Our common future. Oxford, England: Oxford University Press.

(6) City of Vancouver. Definition of Social Sustainability. [On-line] Retrieved 31 July 2006 from http://vancouver.ca/ctyclerk/cclerk/20050524/documents/p1.pdf

(7) Connell, B.R., Jones, M., Mace, R., Mueller, J., Mullick, A., Ostroff, E., Sanford, J.A., Steinfeld, E., Story, M., \& Vanderheiden, G., 1997. The Principles of Universal Design: Version 2.0. Raleigh, North Carolina: The Center for Universal Design, North Carolina State University.

(8) Daly, H E. ed 1973. Toward a Steady State Economy, Freeman, San Francisco, CA.

(9) Daly, H E. 1974. The Economics of the Steady State, Am. Econ. Rev. March, $15-21$.

(10) Daly, H E. 1992. Allocation, Distribution and Scale: Towards an Economics which is Efficient, Just and Sustainable, Ecol. Econ., 6(3), 185-193.

(11) Daly, H E. 1996. Beyond Growth: the Economics of Sustainable Development, Beacon Press, Boston, MA. 
(12) Daly, H E 1999. Ecological Economics and the Ecology of Economics, E Elgar Publications, Cheltenham.

(13) Daly, H E. , Cobb, J B 1989 For the Common Good, Beacon Press, Boston, MA.

(14) El Kony, H. Avril, 1997. Les approches des interventions environnementales pour les personnes ayant des incapacités physiques. Mémoire présenté à la Faculté des Études Supérieures en vue de l'obtention du grade de Maître ès Sciences appliquées M. Sc. A.) en Aménagement. Montréal: Université de Montréal.

(15) El Kony, H. January, 2004. Designing Barrier- Free Environment: Towards and Egyptian approach. Dissertation presented to the Faculty of Fine-Arts to get the Doctoral degree in Architecture. Alexandria: University of Alexandria.

(16) El Kony, H. \& Danford, G.S., 2004. Performance Prediction Model PPM: In quest of an inclusive approach for evaluating Person-Environment Transactions, EDRA 34, Minneapolis, Minnesota.

(17) Gewirth, A., 1983. Human Rights: Essays on Justification and Applications, Chicago: University of Chicago Press.

(18) Ghilarov, A., 1996. What does 'biodiversity' mean - scientific problem or convenient myth? TREE, 11 7), 304-306.

(19) Goodland, R. Sustainability: Human, Social, Economic and Environmental. World Bank, Washington, DC, USA

(20) Hancock, T., Social Sustainability-The "soft infrastructure" of a Healthy Community http://newcity.ca/Pages/social_sustainability.html

(21) Hargroves, K. and M. Smith (Eds.) 2005. The Natural Advantage of Nations: Business Opportunities, Innovation and Governance in the 21st Century. www.thenaturaladvantage.info.

(22) Jones, L., Fowles, D. L., King, E. A. The Mandate for Green/Sustainable Design: Good for People-Good for the Planet Earth, Conference proceedings: Designing for the 21st Century III- An International Conference on Universal Design. 7-12 December, 2004 - Rio de Janeiro, Brazil

(23) Lerner, M.J., 1977. The justice motive. Some hypotheses as to its origins and forms. Journal of personality, 45, 1-52.

(24) Lindberg, Lars: The American Solution, our Future Model of Handicap Policy, Stockholm 1996

(25) Mace, R., 1985. Universal design, barrier-free environments for everyone, Los Angeles: Designers West.

(26) Oliver, M., \& Sapey, B. 1999. Social work with disabled people, London: Macmillan Press Ltd.

(27) Queensland Government, 2004. Smart Housing. Version 1. Department of housing.

(28) Robinson, J.W., Thompson, T.1999. Stigma and Architecture; Enabling environments: measuring the impact of environment on disability and rehabilitation / edited by Edward Steinfeld and G. Scott Danford.

(29) Sandhu, J. S., 2001: An integrated approach to universal design: Towards inclusion of all ages, cultures and diversity. In: Universal Design Handbook. Edited by Wolf Preiser \& Elaine Ostroff. McGraw-Hill, New York . 
(30) Sandhu, J.S., 2002. Multi-Dimensional Evaluation as a Tool in Teaching Universal Design. In: Universal Design: 17 ways of thinking and teaching. Edited by Jon Christophersen, Husbanken, Norway .

(31) Sandhu, Jim: A Holistic Approach to the Design for All Concept, Newcastle 1995

(32) Satterthwaite, David, ed. 1999. The Earthscan Reader in Sustainable Cities. London: Earthscan. An excellent collection of articles with a focus on international and Third World issues.

(33) Toman, M. 1992. The Difficulty in Defining Sustainability. Resources 106 (Winter): 3-6.

(34) 2005 World Summit Outcome Document, World Health Organization, 15 September 2005 from website: http://www.who.int/hiv/universalaccess2010/worldsummit.pdf

(35) United Nations, 2004, Agenda 21: Chapter 7, PROMOTING SUSTAINABLE HUMAN SETTLEMENT DEVELOPMENT

(36) Winhall, J., 2008. Is design political? Core 77, Inc. from http://www.core77.com/reactor/03.06_winhall.asp

(37) Sustainable Design Competition- 2008 Center for Universal Design, College of Design, North Carolina State University

(38) Voinov, A., 1998. Paradoxes of Sustainability. Journal of General Biology , 59, 209-218.

(39) Walter, E., Walster, G. W. \& Berscheid, E., 1978. Equity: Theory and research. Boston: Allyn \& Bacon.

(40) WCED World Commission on Environment and Development, 1987. Our Common Future. Oxford University Press, Oxford, 400 p.

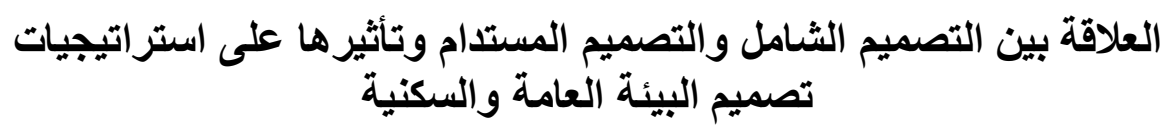

تتعرض الورقة لتوجهين تصميميين منبثقين من مبادئ العدالة الإجتماعية وهما التصميم الثنامل

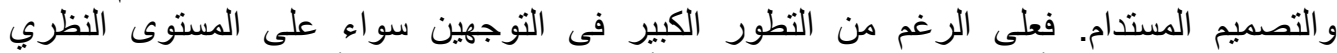

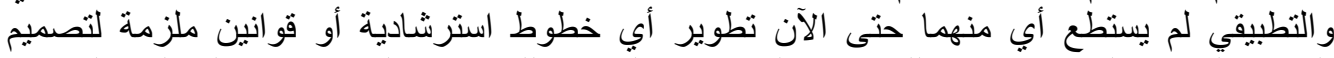

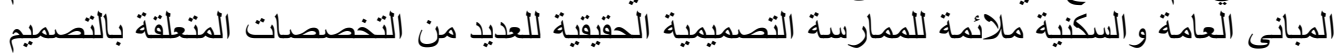

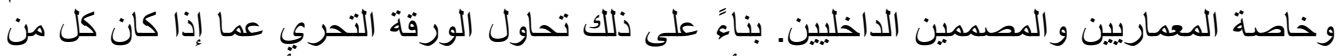

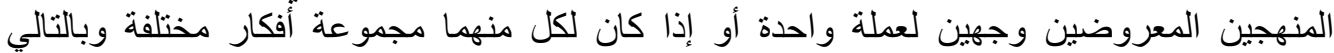

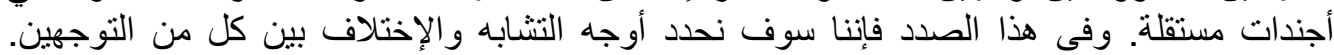

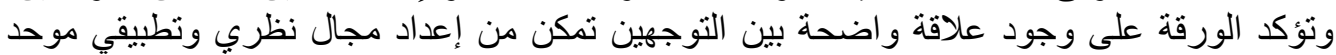

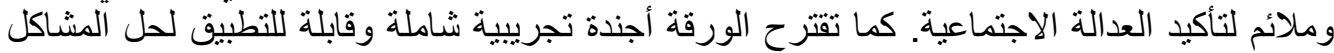

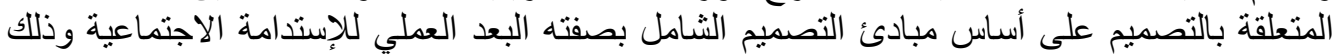

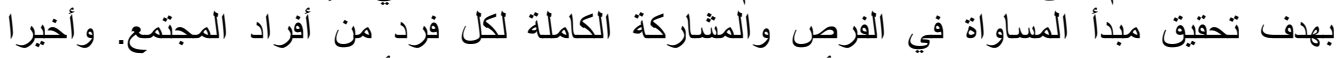
تستعرض الورقة المعوقات التى يمكن أن تحد من إمكانيات تحقيق هذه الأجندة.

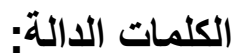
المساو اة الاجتماعية، التصميم الثامل، التصميم المستدام، الاستدامة الاجتماعية، استر اتيجيات التصميم. 